Postprint version. Original publication in:

Journal of Insect Conservation (2009) 13:165-175

doi: http://dx.doi.org/10.1007/s10841-008-9139-4

\title{
Habitat quality matters for the distribution of an endangered leaf beetle and its egg parasitoid in a fragmented landscape
}

\author{
Annette Heisswolf ${ }^{1}$, Stefanie Reichmann ${ }^{1}$, Hans Joachim Poethke ${ }^{1}$, \\ Boris Schröder ${ }^{2}$, Elisabeth Obermaier ${ }^{1}$ \\ ${ }^{1}$ Field Station Fabrikschleichach, University of Würzburg, Glashüttenstrasse 5, D-96181 Rauhenebrach \\ 2 Institute of Geoecology, University of Potsdam, P.O. Box 601553, D-14415 Potsdam
}

\begin{abstract}
Fragmentation, deterioration, and loss of habitat patches threaten the survival of many insect species. Depending on their trophic level, species may be differently affected by these factors. However, studies investigating more than one trophic level on a landscape scale are still rare. In the present study we analyzed the effects of habitat size, isolation, and quality for the occurrence and population density of the endangered leaf beetle Cassida canaliculata Laich. (Coleoptera: Chrysomelidae) and its egg parasitoid, the hymenopteran wasp Foersterella reptans Nees (Hymenoptera: Tetracampidae). C. canaliculata is strictly monophagous on meadow sage (Salvia pratensis), while F. reptans can also parasitize other hosts. Both size and isolation of habitat patches strongly determined the occurrence of the beetle. However, population density increased to a much greater extent with increasing host plant density (= habitat quality) than with habitat size. The occurrence probability of the egg parasitoid increased with increasing population density of $C$. canaliculata. In conclusion, although maintaining large, well-connected patches with high host plant density is surely the major conservation goal for the specialized herbivore $C$. canaliculata, also small patches with high host plant densities can support viable populations and should thus be conserved. The less specialized parasitoid $F$. reptans is more likely to be found on patches with high beetle density, while patch size and isolation seem to be less important.
\end{abstract}

Keywords. Habitat fragmentation, herbivore, host plant density, metapopulation, multitrophic.

\section{INTRODUCTION}

All over the world the persistence of rare animal and plant species is threatened by loss and fragmentation of habitats due to massive human interference in the environment (Fahrig, 2001; Hunter, 2002; Fahrig, 2003; Ewers \& Didham, 2006). In Central Germany, insect populations face a fragmented landscape in which suitable habitat patches 
are interspersed between areas of intensive agricultural land use. To successfully predict the occurrence patterns of endangered species and in order to choose effective conservation strategies, we need to analyze which patch features are most important for the respective species. In this context, metapopulation variables such as patch size and isolation but also different aspects of habitat quality must be considered (e.g. Dennis \& Eales, 1997; Thomas et al., 2001; Fleishman et al., 2002; Tscharntke et al., 2002; Hanski \& Gaggiotti, 2004; Dennis et al., 2006).

Metapopulation theory states that the populations of a species are interdependent within a landscape and that long-term persistence depends on a balance across the landscape between local extinctions of individual populations and new colonizations of vacant habitat patches (Hanski, 1998; Moilanen \& Hanski, 1998). Based on this theory, the occurrence probability of a species within a patch is supposed to increase with increasing patch size and decreasing isolation, as both raise the probability that dispersing animals will find a patch. Patch size also has a positive effect on the survival probability of a population within a patch, as larger patches usually support larger populations (Hanski \& Gaggiotti, 2004).

Additionally, several recent studies emphasized that the quality of a habitat patch also influences its carrying capacity and may thus affect the survival chance of a population (Clarke et al., 1997; Dennis \& Eales, 1997; Thomas et al., 1998; Wiegand et al., 1999; but see Haynes et al. 2007). Consequently, Thomas et al. (2001) suggested that habitat quality is the missing third variable in metapopulation dynamics. They hypothesized that habitat quality and spatial effects operate at different hierarchical levels within the same process: while patch size and isolation can be important for the (re-) colonization probability of a patch, habitat quality is supposed to contribute to species persistence within a patch.

Furthermore, the survival of a species does not only depend on its resources, but also on the impact of natural enemies. Thus, it is of critical importance to take also higher trophic levels into account Hunter (2002); Cronin \& Reeve (2005). Still, the majority of studies on insect (meta-)populations focus on just one trophic level and only recently multi-trophic level interactions have been investigated in a metapopulation context (Eber, 2001; van Nouhuys \& Hanski, 2002). Our study is one of the first that analyzes the importance of patch size, isolation, and habitat quality for the occurrence and persistence of a herbivore and its parasitoid in a fragmented landscape.

The herbivorous leaf beetle Cassida canaliculata Laich. (Coleoptera: Chrysomelidae) has in the past been quite common in Germany (Bach, 1851; Steinhausen, 1949). Today, it is classified as 'vulnerable' (VU) in the red list of Germany (Bundesamt für Naturschutz, 1998) and even as 'critically endangered' (CE) in the red list of Bavaria (Bayerisches Landesamt für Umweltschutz, 2003). However, in the nature re- 
serve 'Hohe Wann' in Northern Bavaria, Germany (50 $\left.03^{\circ} \mathrm{N}, 10^{\circ} 35^{\prime} \mathrm{E}\right)$ we found the species to be locally abundant. This gave us an excellent opportunity to study the needs of $C$. canaliculata in relatively favorable conditions.

C. canaliculata is strictly monophagous on meadow sage (Salvia pratensis L., Lamiales: Lamiaceae) (Wencker \& Silbermann, 1866; Bourgeois \& Scherdlin, 1899; Reitter, 1912; Graser, 1984; Trautner et al., 1989; A. Heisswolf and D. Gabler, unpublished data) and can thus only survive on patches where $S$. pratensis occurs. A description of the life cycle of $C$. canaliculata can be found in Heisswolf et al. (2005). The egg clutches of the beetle are heavily parasitized (up to $70 \%$ of all egg clutches per patch; Heisswolf et al. 2006 and unpublished data) by the hymenopteran wasp Foersterella reptans Nees (Hymenoptera: Tetracampidae). F. reptans can also parasitize other Cassida species, e.g., Cassida rubiginosa Müller (Bacher \& Luder, 2005). However, the occurrence and distribution of other Cassida species in the nature reserve 'Hohe Wann' have not yet been investigated.

We tested two hypotheses for both the herbivore $C$. canaliculata and the parasitoid F. reptans. (1) The occurrence probability of each species will increase with increasing patch size and with decreasing patch isolation, as both raise colonization success. (2) For both species, population density will increase with increasing patch size and with increasing habitat quality as both determine the carrying capacity of the patch (Thomas et al., 2001; Fleishman et al., 2002; Hanski \& Ovaskainen, 2003).

\section{MATERIALS AND METHODS}

\section{Study site}

The area of the 'Hohe Wann' nature reserve covers approximately $10 \mathrm{~km}$ in NSdirection and $4 \mathrm{~km}$ in EW-direction (Rudner et al., 2007). The nature reserve is characterized by a patchwork of different habitat types due to the geological and geomorphological heterogeneity of the area, agricultural land use, and small-scale microclimatic differences resulting from different exposure, inclination, and land use (Elsner, 1994). Crop land (37\%) and forest (23\%) cover the largest part of the area. Habitat types suitable for the leaf beetle's only host plant meadow sage, S. pratensis, are dry grasslands (3\% coverage), extensively managed meadows $(6 \%)$, intensively managed poor meadows (5\%), and intensively managed meadows (5\%). Absolute and relative coverage of the nine main habitat types (according to Hein et al. 2007) occurring in the nature reserve are included in Appendix A. A detailed description of all habitat types can be found in Hein et al. (2007) and a map showing the distribution of habitat types in the nature reserve is included in Rudner et al. (2007). 
Prior to the present study, the occurrence of $S$. pratensis was recorded within the whole nature reserve and a habitat map for $S$. pratensis was developed (S. Reichmann, unpublished data), which consisted of 161 different potential habitat patches for $C$. canaliculata. Within these patches, 77 random points were selected (max. one per patch) using the Geographical Information System Arc View GIS 3.2 (ESRI). These 77 patches belonged to the habitat types dry grasslands (28), extensively managed meadows (30), intensively managed poor meadows (12), and intensively managed meadows (7). The size of the patches ranged from 1.20 to 105.64 ha (mean $\pm 95 \%$ confidence limit: $18.32 \pm 5.05 \mathrm{ha}$ ). In the field, we located the points using a portable GPS. The number of patches which we included in the analyses depended on the variables used (not all predictor variables were available for all 77 patches) and is mentioned separately with each model.

\section{Habitat quality}

For C. canaliculata, we measured four variables as potential predictors of habitat quality. (1) Mean host plant (S. pratensis) size, which was a principal component derived from the variables rosette diameter $(\mathrm{cm})$, rosette height $(\mathrm{cm})$, and number of vegetative cones, (2) host plant density $\left(\mathrm{m}^{-2}\right)$, (3) patch exposure, which was a principal component derived from the variables cosine-transformed aspect and potential solar irradiation $\left(\mathrm{kWh} / \mathrm{m}^{2}\right)$, and (4) patch slope (degrees). Appendices B and C show the eigenvectors and eigenvalues of the two principal components analyses. We considered patch exposure and slope as variables describing habitat quality, because they both influence the microclimate of a patch: steep and south-facing patches are expected to have a warmer microclimate and may thus provide better growth conditions for larvae in spring. For obtaining predictors (1) and (2), we randomly selected 10 squares of $1 \mathrm{~m}^{2}$ size within a circle $(r=11 \mathrm{~m})$ around the random point (see above). Within these squares, we counted all host plants and measured the rosette diameter, rosette height, and number of vegetative cones of 30 randomly selected host plants (three per square). The data from the 30 plants per patch were then averaged to obtain one value per patch. Predictors (3) and (4) were obtained from a digital terrain model (grid size 5 m, cf. Rudner et al. 2007). Habitat quality variables, which we analyzed for $F$. reptans, were (1) egg clutch density of $C$. canaliculata (see below), (2) density of $S$. pratensis plants, (3) patch exposure, and (4) patch slope.

\section{Patch size}

We derived patch size (ha) from aerial photographs by means of GIS analysis. In addition, we used the radius of gyration (m), $R$ (Eq. 1), which is defined as the mean distance between the center of each grid cell $\left(x_{i}, y_{i}\right)$ within a patch $(n=$ number of grid 
cells) and the patch center $(x, y)$ (after Keitt et al. 1997), to integrate patch shape into a further measure of patch size.

$$
R=\frac{1}{n} \sqrt{\left(x_{i}-\bar{x}\right)^{2}+\left(y_{i}-\bar{y}\right)^{2}}
$$

Finally, we calculated the perimeter-to-area ratio of each patch. We obtained both the radius of gyration and the perimeter-to-area-ratio using the software Fragstats 3.3 (McGarigal, 2001).

\section{Patch isolation}

To the authors' knowledge, nothing is yet known about dispersal in both $C$. canaliculata and $F$. reptans. This makes it difficult to study isolation effects in both species. As a first approach, we used two different patch isolation metrics for $C$. canaliculata. (1) The shortest edge-to-edge distance $(\mathrm{m})$ to the 'nearest neighbor' patch with $C$. canaliculata occurrence. (2) The connectivity $S_{i}$ after Hanski (1998) (Eq. 2), where $P_{j}$ is the occurrence of $C$. canaliculata in patch $j, A_{j}$ is the size (ha) of patch $j, d_{i j}$ is the shortest center to center distance (m) of patches $i$ and $j$ (which are assumed to be circular), and $\alpha=1 / 2 D$, where $D$ is the mean dispersal distance (m) of $C$. canaliculata.

$$
S_{i}=\sum_{j=1}^{n} P_{j} e^{\left(-\alpha d_{i j}\right)} A_{j}
$$

The mean dispersal distance is also unknown for C. canaliculata, but we assumed it to be $50 \mathrm{~m}$, since the beetles move mainly by walking rather than by flying ( $\mathrm{S}$. Reichmann and A. Heisswolf, personal observations). F. reptans, which has a body length of only $1 \mathrm{~mm}$, is probably not capable of active flight, but may be drifted over far distances with the wind. Thus, any estimation of a mean dispersal distance did not seem reasonable without further information on that species. Therefore, we only used the distance to the nearest neighbor patch with occurrence of $F$. reptans as a first approximation of isolation effects. We obtained variable (1) using the GIS and we calculated variable (2) using the software Isolator 1.3 (R. Biedermann, personal communication).

\section{Species incidence and density}

To obtain a measure for egg clutch density of $C$. canaliculata we counted the number of egg clutches on the 30 above-mentioned plants per patch. This measure was also used as a proxy for population density of $C$. canaliculata. If no egg clutches were found on these 30 plants, the whole patch was thoroughly searched for egg clutches to ensure that the patch was truly not occupied by the beetle. To measure parasitism by 
F. reptans, we collected 10 egg clutches of $C$. canaliculata per site (if available) and checked them for hatching parasitoids in the laboratory.

\section{Statistics}

We calculated all statistical procedures using the software package R 2.2.1 (R Development Core Team, 2005). Prior to analysis, we tested all predictors for bivariate correlation using Spearman rank-correlations (Appendices D and E). We included only those variables into the same multiple model whose correlation coefficient $\left(\rho_{S}\right)$ was less than 0.1 . We combined the correlated variables $\left(\rho_{S} \leq 0.5\right)$ mean rosette diameter, rosette height, and number of vegetative cones as well as exposure and potential solar irradiation to principal components using principal components analysis (Mardia et al., 1979; Venables \& Ripley, 2002; cf. Appendices B and C).

We estimated the occurrence probability of $C$. canaliculata and $F$. reptans within a patch in two steps. First, we applied hierarchical partitioning methods (Mac Nally, 2000, 2002; Heikkinen et al., 2005) to determine the independent explanatory power of the predictors, using the R package 'hier.part' (Walsh \& Mac Nally, 2007). Then, we analyzed all possible combinations of all variables (including interactions) that had a significant independent effect (after bootstrapping) with multiple logistic regression models (Hosmer \& Lemeshow, 2000), using the R packages 'Design' (Harrell, 2005 ) and 'Hmisc' (Harrell 2006). In order to evaluate the goodness-of-fit of the models we considered the pseudo- $R^{2}$ after Nagelkerke (1991) $\left(R_{\text {Nagelkerke }}^{2}\right)$. We used ROC plots (receiver operating characteristics), or more specifically, the area under the resulting curve ('area under curve' = AUC), to determine the classification accuracy of the model (Hanley \& McNeil, 1982; Swets, 1988). We calculated AUC-values with a 95\% confidence interval applying a software provided by Schröder (2006). This software is used to assess model transferability by testing the significance of AUC-values after applying the model to independent test data (e.g. Binzenhöfer et al., 2005). To achieve unbiased estimates of $R_{\text {Nagelkerke }}^{2}$ and AUC-values for multiple regression models we applied internal validation via bootstrapping (Harrell, 2001).

We tested the correlations between all variables and population density of $C$. canaliculata or rate of parasitism by $F$. reptans using multiple linear regression models. Again, we pre-selected variables for multiple models based on hierarchical partitioning. To evaluate the goodness-of-fit of the models and to compare multiple models, we used the adjusted coefficient of determination $R^{2}$.

For all analyses, we compared different models with the same response variable via the Akaike Information Criterion corrected for small sample sizes ( $\mathrm{AIC}_{c}$; Burnham \& Anderson, 2002), which allows choosing the model with the optimal compromise between goodness of fit and model complexity. 


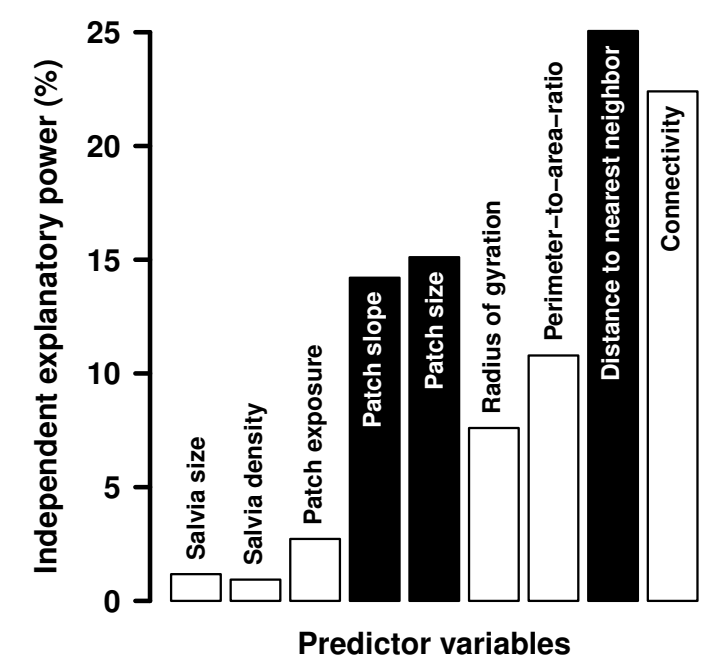

Figure 1: Predictor variables explaining the occurrence of $C$. canaliculata. Percentage distribution of independent explanatory power of all tested predictor variables calculated by hierarchical partitioning. The tested variables were Salvia size (principal component), Salvia density, patch exposure (principal component), patch slope, patch size, radius of gyration, perimeter-to-area-ratio, distance to the nearest neighbor, and connectivity. Variables that were included in the best multiple logistic regression model are shaded in black.

\section{RESULTS}

\section{Occurrence of C. canaliculata}

We found egg clutches of $C$. canaliculata on 47 of 77 potential habitat patches (with occurrence of the host plant $S$. pratensis). Consequently, the prevalence of $C$. canaliculata was $61 \%$. Hierarchical partitioning showed that patch isolation (nearest neighbor or connectivity), patch size, and patch slope had a significant independent explanatory power for C. canaliculata occurrence, while the other tested variables seemed to be of less relevance (Figure 1).

Subsequent multiple logistic regression modeling resulted in seven significant models (Table 1). The model with the lowest $A I C_{c}$-value consisted of the variables patch slope, patch size, and distance to the nearest neighbor (NN) (intercept $\pm \mathrm{SE}$ $=-1.08 \pm 1.05$, coefficient [patch slope] $\pm \mathrm{SE}=0.148 \pm 0.080$, coefficient [patch size $] \pm \mathrm{SE}=0.060 \pm 0.029$, coefficient $[\mathrm{NN}] \pm \mathrm{SE}=-0.007 \pm 0.003$; Table 1). The predicted probability of occurrence calculated by this model and the observed occurrence of $C$. canaliculata for all studied habitat patches match very well for the majority of all studied patches (Figure 2). Furthermore, response surface plots show the predicted occurrence probability of $C$. canaliculata depending on the model predictors patch slope, patch size, and distance to the nearest neighbor patch (Figure 3). 
The occurrence probability of $C$. canaliculata increased with increasing patch slope and size, as well as with decreasing distance to the nearest neighbor patch.

\section{Population density of C. canaliculata}

Hierarchical partitioning showed that both host plant (Salvia) density and patch size strongly influence the population density of $C$. canaliculata, although Salvia density had a more than three times higher independent explanatory power (51\%) than patch size (15\%, Figure 4). A subsequent multiple linear regression model including both variables, Salvia density and patch size, highly significantly explained the population density increase of $C$. canaliculata (intercept $\pm \mathrm{SE}=-0.140 \pm 0.103$, coefficient $[$ Salvia density] $\pm \mathrm{SE}=0.043 \pm 0.012$, coefficient [patch size] $\pm \mathrm{SE}=0.010 \pm 0.002$, $P<0.0001, F=14.63, R^{2}=0.316, A I C=71.52, N=60$ patches $)$.

\section{Parasitism by F. reptans}

We observed parasitism of $C$. canaliculata egg clutches by the hymenopteran wasp $F$. reptans on 17 of the 31 patches $(55 \%)$ where $C$. canaliculata occurred and on which ten egg clutches could be collected. The only variable that significantly explained the occurrence of $F$. reptans was egg clutch density of $C$. canaliculata (intercept $\pm \mathrm{SE}$ $=-0.778 \pm 0.588$, coefficient $\pm \mathrm{SE}=1.804 \pm 0.947, P=0.022, R_{N}^{2}=0.207, A U C \pm$ $95 \% \mathrm{CI}=0.788 \pm 0.186, N=31$ patches), which is a variable describing habitat quality. The percentage of parasitism of the 10 collected egg clutches per site ranged from 10 to $60 \%$ (mean: $25.9 \pm 4.4 \%$ ). However, none of the studied variables correlated significantly with the parasitism rate of $F$. reptans.

Table 1: Significant multivariate logistic regression models of the occurrence of $C$. canaliculata depending on combinations of predictors of habitat quality (slope), habitat size (patch size), and habitat isolation (distance to nearest neighbor $=\mathrm{NN}$, connectivity). Given are the $P$-value, $\chi^{2}$-value, $R_{\text {Nagelkerke }}^{2}, A I C_{c^{-}}$, and $A U C$-value (after internal validation via bootstrapping), as well as the number $(N)$ of study sites that were included in the analysis. The model with the lowest $A I C_{c}$ is printed in bold letters.

\begin{tabular}{lrrrrrr}
\hline Parameter & $P$ & $\chi^{2}$ & $R_{N}^{2}$ & $A I C$ & $A U C$ & $N$ \\
\hline Slope + patch size & 0.0055 & 6.72 & 0.158 & 80.67 & 0.695 & 64 \\
Slope + NN & 0.0015 & 8.38 & 0.205 & 78.07 & 0.707 & 64 \\
Slope + connectivity & 0.0050 & 7.46 & 0.150 & 80.47 & 0.720 & 64 \\
Patch size + NN + patch size $\times$ NN & 0.0005 & 7.77 & 0.221 & 93.56 & 0.731 & 77 \\
Patch size + connectivity & 0.0002 & 9.55 & 0.228 & 92.19 & 0.748 & 77 \\
Slope + patch size + NN & $\mathbf{0 . 0 0 0 1}$ & $\mathbf{1 0 . 5 7}$ & $\mathbf{0 . 3 1 5}$ & $\mathbf{7 2 . 6 7}$ & $\mathbf{0 . 7 6 7}$ & $\mathbf{6 4}$ \\
Slope + patch size + connectivity & 0.0003 & 9.80 & 0.262 & 74.49 & 0.775 & 64 \\
\hline
\end{tabular}




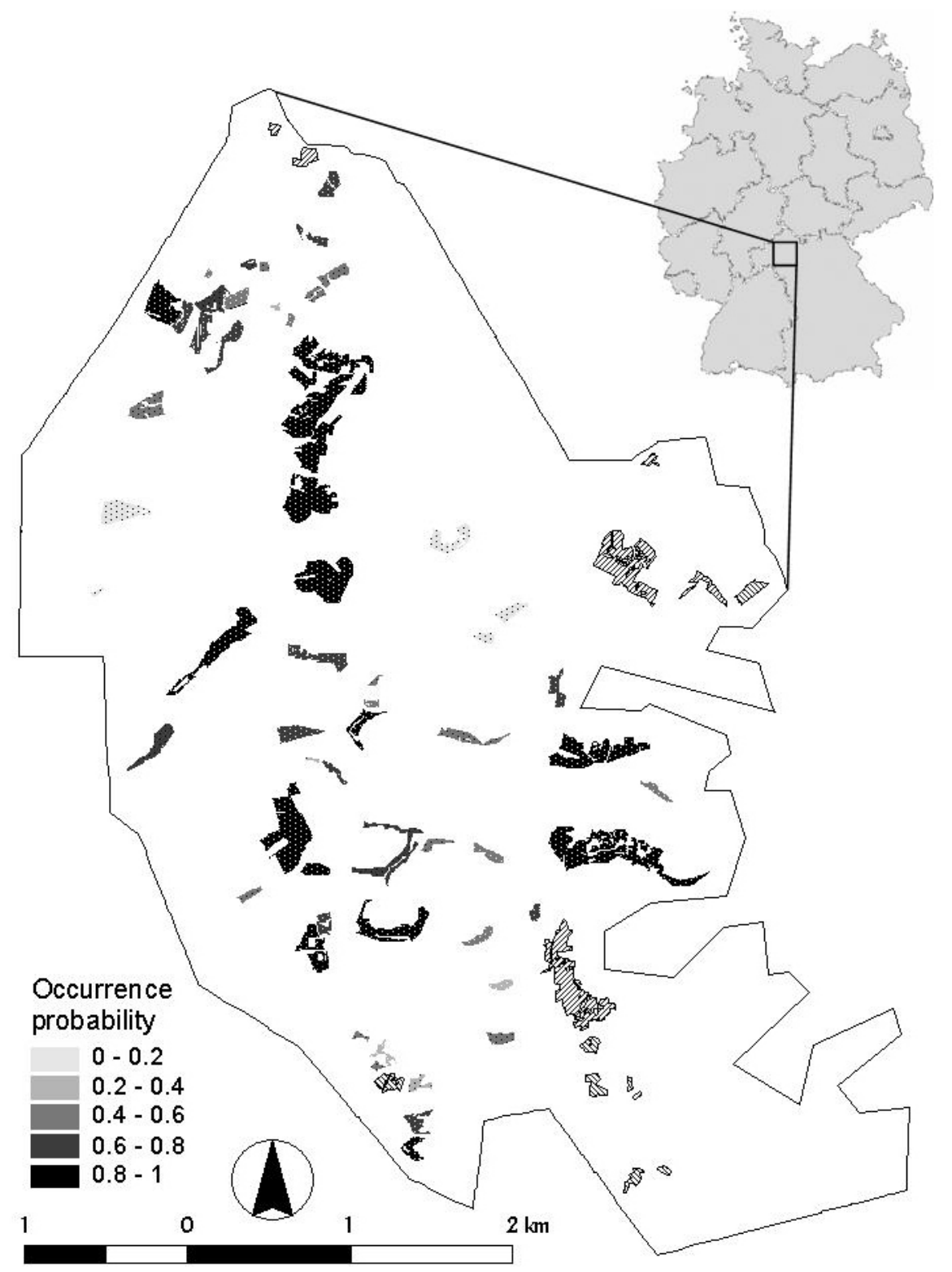

Figure 2: Predicted and observed occurrence of $C$. canaliculata within the Hohe Wann nature reserve. The map shows the distribution of the 77 studied potential habitat patches with occurrence of the host plant $S$. pratensis. Additionally, a small map of Germany shows the approximate location of the nature reserve within Germany. The studied patches are colored in different shades of gray corresponding to the occurrence probabilities of $C$. canaliculata predicted by the multiple logistic regression model depending on the variables patch slope, patch size, and distance to the nearest neighbor. White (presence) and black (absence) dots on the respective patches indicate the observed occurrence of $C$. canaliculata. Patches on which the presence or absence of $C$. canaliculata were registered, but which could not be included into the multiple model due to the lack of area-wide data are not shaded but are horizontally hatched (presence) or vertically hatched (absence). 


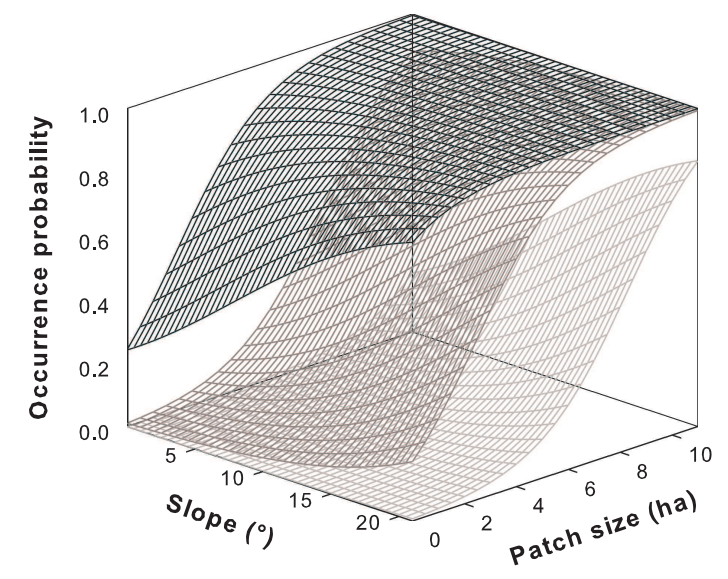

Figure 3: Response surfaces of habitat suitability models for $C$. canaliculata considering the predictor variables patch size (ha), patch slope $\left(^{\circ}\right)$, and distance to the nearest neighbor patch $(\mathrm{m})$, The occurrence probability of $C$. canaliculata is plotted depending on patch slope and patch size for three exemplary distances to the nearest neighbor patch: $10 \mathrm{~m}$ (black), $500 \mathrm{~m}$ (dark gray), and $1000 \mathrm{~m}$ (light gray).

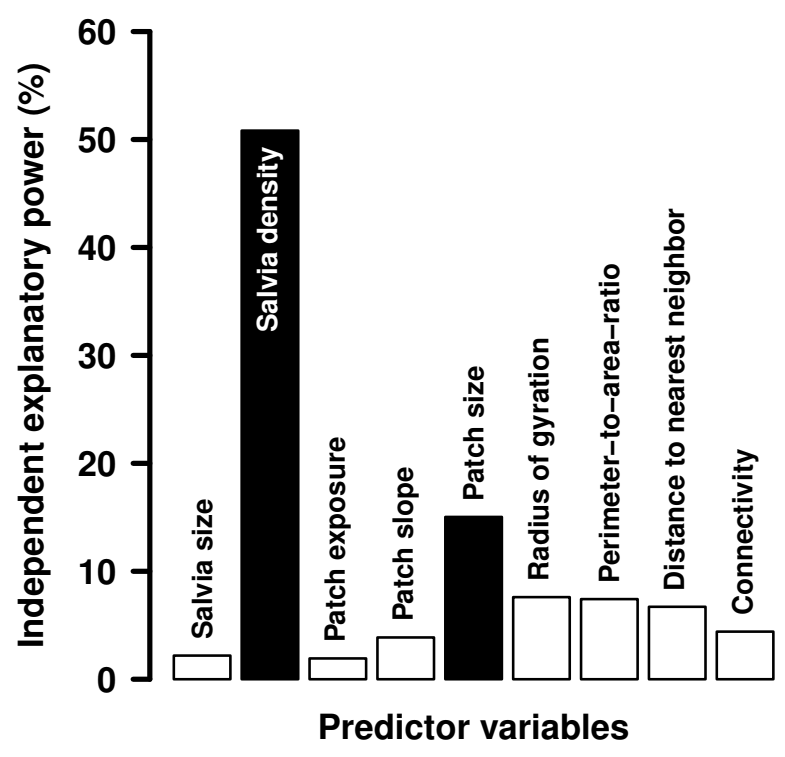

Figure 4: Predictor variables explaining the population density of $C$. canaliculata. Percentage distribution of independent explanatory power of all tested predictor variables calculated by hierarchical partitioning. The tested variables were Salvia size (principal component), Salvia density, patch exposure (principal component), patch slope, patch size, radius of gyration, perimeter-to-area-ratio, distance to the nearest neighbor, and connectivity. Variables that were included in the best multiple model are shaded in black. 


\section{DisCUSSION}

Patch size and isolation as well as patch slope were the most important factors determining the occurrence pattern of the endangered leaf beetle Cassida canaliculata within the habitat patch network in this study. The population density of the beetles was strongly determined by host plant density and patch size. Patch shape and other habitat quality variables did not contribute significantly to the explanation of beetle occurrence or density. This indicates that a network of large and well-connected habitat patches with high host plant densities is an apparent conservation goal. Nevertheless, as host plant density had a more than three times higher explanatory effect on population density than patch size, also small patches with high host plant densities can support viable populations and should thus be sustained as well. The egg parasitoid Foersterella reptans occurred most likely on patches with high population densities of the beetle. However, we could not find any significant correlation between beetle population density and percentage of parasitized egg clutches. Thus, the risk of any single beetle egg clutch being parasitized seemed not to depend on egg clutch density. Patch size, isolation, and other habitat quality variables were not correlated to parasitoid occurrence or density.

In accordance with metapopulation theory (Hanski \& Gaggiotti, 2004), the occurrence probability of $C$. canaliculata correlated positively with patch size and negatively with patch isolation. Additionally, patch shape may be essential, as edge effects at the patch border can have a negative impact on species survival within a patch (Tscharntke et al., 2002; Ewers \& Didham, 2006). Thus, patches with a small perimeter-to-area-ratio may have a higher occurrence probability. This was, however, not the case in our study. Both this and the fact that patch size had a two times higher independent explanatory power (15\%) for the occurrence of the leaf beetle on a patch than the radius of gyration (8\%) suggest that linear landscape elements, which may serve as corridors for other species (Rosenberg et al., 1997; Berggren et al., 2002), do not seem to play an important role for $C$. canaliculata.

Concerning patch isolation, the variables distance to the nearest neighbor and connectivity describe the isolation of a patch in a qualitatively different way. The distance to the nearest neighbor patch with $C$. canaliculata occurrence gives no information on the size of this patch and on how many other patches are located nearby, whereas the connectivity integrates the size and distance of all potential source patches within a landscape (cf. Kuhn \& Kleyer, 1999/2000). In a recent meta-analysis, Moilanen \& Nieminen (2002) recommended that complex connectivity measures should be preferred over simple measures (like the distance to the nearest neighbor), as simple measures often fail to detect effects of isolation, which could be detected with measures that are more complex. In the present study, both the simple measure distance to the 
nearest neighbor and the more complex measure connectivity could be used to explain the occurrence of $C$. canaliculata within a patch. However, as the distance to the nearest occupied neighbor patch requires no information on the dispersal ability of $C$. canaliculata it should be preferred over the more complex connectivity measure until more detailed knowledge is available on dispersal distances in this species. A still better measure of patch isolation from the beetles' view should also include the structure of the 'matrix' into which the potential habitat patches are embedded (Gustafson \& Gardner, 1996; Ricketts, 2001; Goodwin \& Fahrig, 2002; Ewers \& Didham, 2006). Habitat patches that have the same distances to the 'nearest neighbor' may be differently isolated depending on the surrounding matrix structure. This issue has to be addressed in future studies on C. canaliculata.

Regarding habitat quality, only patch slope contributed significantly to the occurrence probability of the beetle. There are several possible explanations for this result. One of them relates to the microclimate of the patch, as steeper patches could have a warmer microclimate favoring the development of the beetle larvae in early spring. However, this holds only for patches facing south and west, whereas slope usually reduces irradiation on north or east facing patches. Moreover, very steep slopes almost always decrease the irradiation of patches. Therefore, it is rather unlikely that slope itself is a good predictor of microclimate. Another possible explanation for the positive correlation between patch slope and beetle occurrence could be that steep patches may be less often disturbed by management than shallow patches and may thus provide better conditions for the long-term survival of populations. A third possibility of an effect of patch slope could be related to the drainage of soil water, which could be important for the abundance and quality of the beetles' host plant $S$. pratensis, which favors dry meadows. However, as we have no detailed information on neither management intensity nor water drainage in relation to patch slope in the study area, both hypotheses remains speculative. Thus, we cannot finally elucidate the meaning of patch slope for the occurrence of $C$. canaliculata within the scope of this study.

While the influence of habitat quality on $C$. canaliculata occurrence remains to be investigated in more detail, there was a clear correlation between habitat quality and population density of $C$. canaliculata. Egg clutch density of $C$. canaliculata, which we used as a measure of population density within a patch, increased not only with patch size but even more with host plant density. Consequently, large habitats with high host plant densities supported larger populations of $C$. canaliculata. In contrast to other studies (Bach, 1988; Connor et al., 2000; Krauss et al., 2004, 2005) patch size and host plant density were not correlated $\left(\rho_{S}=-0.008\right)$ in our study area. Consequently, viable populations of $C$. canaliculata may also persist on smaller patches with high host plant densities (cf. Thomas et al., 2001). Therefore, it is not only important to protect large 
habitats but also to maintain smaller patches with high host plant densities to facilitate the survival of $C$. canaliculata within fragmented landscapes.

Regarding the egg parasitoid, only the egg clutch density of $C$. canaliculata affected the occurrence of Foersterella reptans. The probability of parasitism was positively density dependent. The beetles seem to have a low parasitism risk only when their own population density is low. Above a certain threshold, parasitoids were almost always present. Thus, the beetles do not have very good chances of escaping parasitism within the habitat patch network of this study.

None of the other studied predictors significantly explained variation in the occurrence or density of $F$. reptans. One possible reason for this lack of correlation may be that $F$. reptans can also parasitize other Cassida species (e.g., C. rubiginosa Müller; Bacher \& Luder 2005), and therefore variables of habitat quality, size, and isolation which were appropriate with regard to its host $C$. canaliculata - may have not been comprehensive enough for the perspective of the parasitoid. To the authors' knowledge, $C$. rubiginosa is the only other potential host of $F$. reptans in the study area. C. rubiginosa lives on thistles (Asteraceae: Carduae), which only very rarely grow in the same habitat as $S$. pratensis, the host plant of $C$. canaliculata. Therefore, the patches on which no parasitoids could be found from egg clutches of $C$. canaliculata were most likely really parasitoid-free (keeping in mind that it is per se impossible to 'prove' the absence of a species from a patch). Other potentially suitable patches with $C$. rubiginosa occurrence were not studied. Consequently, we cannot assess their spatial configuration and whether some of them might have been so close to patches classified as 'parasitoid-free' that they might have formed continuous patches from the perspective of the parasitoid. Moreover, even if $F$. reptans would parasitize only $C$. canaliculata the spatial scales affecting herbivore and parasitoid may be nevertheless different (Tscharntke \& Brandl, 2004; Cronin \& Reeve, 2005; Heisswolf et al., 2006). Therefore, the parasitoid may perceive both patch size and isolation quite differently than its host(s). Only detailed studies on the distribution of all other potential hosts and on the dispersal abilities of $F$. reptans may lead to a better estimation of these variables for the parasitoid.

In summary, our study corroborates the hypothesis of e.g., Dennis \& Eales (1997) and Thomas et al. (2001) that habitat quality is as important for the survival of insect species in fragmented landscapes as patch size and isolation. While all three variables, patch quality, size, and isolation determined the occurrence of $C$. canaliculata, habitat quality had the strongest effect on population density. Thus, we recommend to preserve not only large habitat patches, but also to maintain large host plant densities in all potential habitat patches independent of patch size to enhance the survival of $C$. canaliculata. In order to reduce isolation effects, more detailed studies on the disper- 
sal ability of $C$. canaliculata as well as information about the isolation potential of different matrix types are needed. The egg parasitoid $F$. reptans occurred primarily on patches with high egg clutch densities of $C$. canaliculata. However, as there are still several open questions left regarding the parasitoid, further investigations on this species are necessary to determine how $F$. reptans affects the population dynamics and survival of $C$. canaliculata within the Hohe Wann nature reserve.

\section{ACKNOWLEDGements}

We are grateful to Robert Biedermann for providing the 'Isolator' software and to Thomas Hovestadt and Oliver Mitesser for statistical advice. Thomas O. Crist as well as an anonymous referee gave valuable comments on an earlier version of this manuscript. We thank the government of Lower Franconia (Bavaria, Germany) for the permission to work and to collect beetles in the nature reserve. This study used results from the MOSAIK-project which was financially supported by the German Federal Ministry of Education and Research (BMBF, grant 01LN 0007). A. Heisswolf was financially supported through a scholarship granted by the Evangelisches Studienwerk e.V. Villigst. 


\begin{tabular}{|c|c|c|}
\hline \multicolumn{3}{|c|}{ APPENDIX A } \\
\hline \multicolumn{3}{|c|}{ area, the Hohe Wann nature reserve (Northern Bavaria, Germany; $50^{\circ} 03^{\prime} \mathrm{N}, 1$} \\
\hline ta). & & \\
\hline Biotope type & Area (ha) & Proportion cover (\%) \\
\hline Crop land & 772.79 & 36.46 \\
\hline Fallow land & 228.74 & 10.79 \\
\hline Intensively managed meadows & 107.83 & 5.09 \\
\hline Intensively managed poor meadows & 101.25 & 4.78 \\
\hline Dry grassland & 55.59 & 2.62 \\
\hline Extensively managed meadows & 129.80 & 6.12 \\
\hline Fringe vegetation & 18.34 & 0.86 \\
\hline Hedges & 103.93 & 4.90 \\
\hline Forest & 487.43 & 22.99 \\
\hline
\end{tabular}

\section{APPENDiX B}

Eigenvectors, eigenvalues, and explained variance of a principal components analysis including the predictor variables rosette diameter $(\mathrm{cm})$, rosette height $(\mathrm{cm})$, and number of vegetative cones.

\begin{tabular}{lrrr}
\hline & PC 1 & PC 2 & PC 3 \\
\hline Rosette diameter $(\mathrm{cm})$ & -0.918 & 0.058 & -0.392 \\
Rosette height $(\mathrm{cm})$ & -0.861 & 0.357 & 0.364 \\
Number of vegetative cones & -0.407 & -0.906 & 0.114 \\
Eigenvalues & 1.748 & 0.953 & 0.299 \\
\% Variance explained & 58.3 & 31.7 & 10.0 \\
\hline
\end{tabular}




\section{APPEndix C}

Eigenvectors, eigenvalues, and explained variance of a principal components analysis including the predictor variables potential solar irradiation $\left(\mathrm{kWh} / \mathrm{m}^{2}\right)$ and exposure $\left(^{\circ}\right)$.

\begin{tabular}{lrr}
\hline & PC 1 & PC 2 \\
\hline Potential solar irradiation $\left(\mathrm{kWh} / \mathrm{m}^{2}\right)$ & 0.985 & -0.170 \\
Exposure $\left({ }^{\circ}\right)$ & -0.985 & -0.170 \\
Eigenvalues & 1.942 & 0.058 \\
\% Variance explained & 97.1 & 2.89 \\
\hline
\end{tabular}

\section{APPENDIX D}

Bivariate Spearman-rank correlations of all predictor variables and principal components (PC) used for explaining the occurrence and density of the herbivore $C$. canaliculata. The correlation coefficient $\rho_{S}$ is given (values $>0.5$ are shaded in gray).

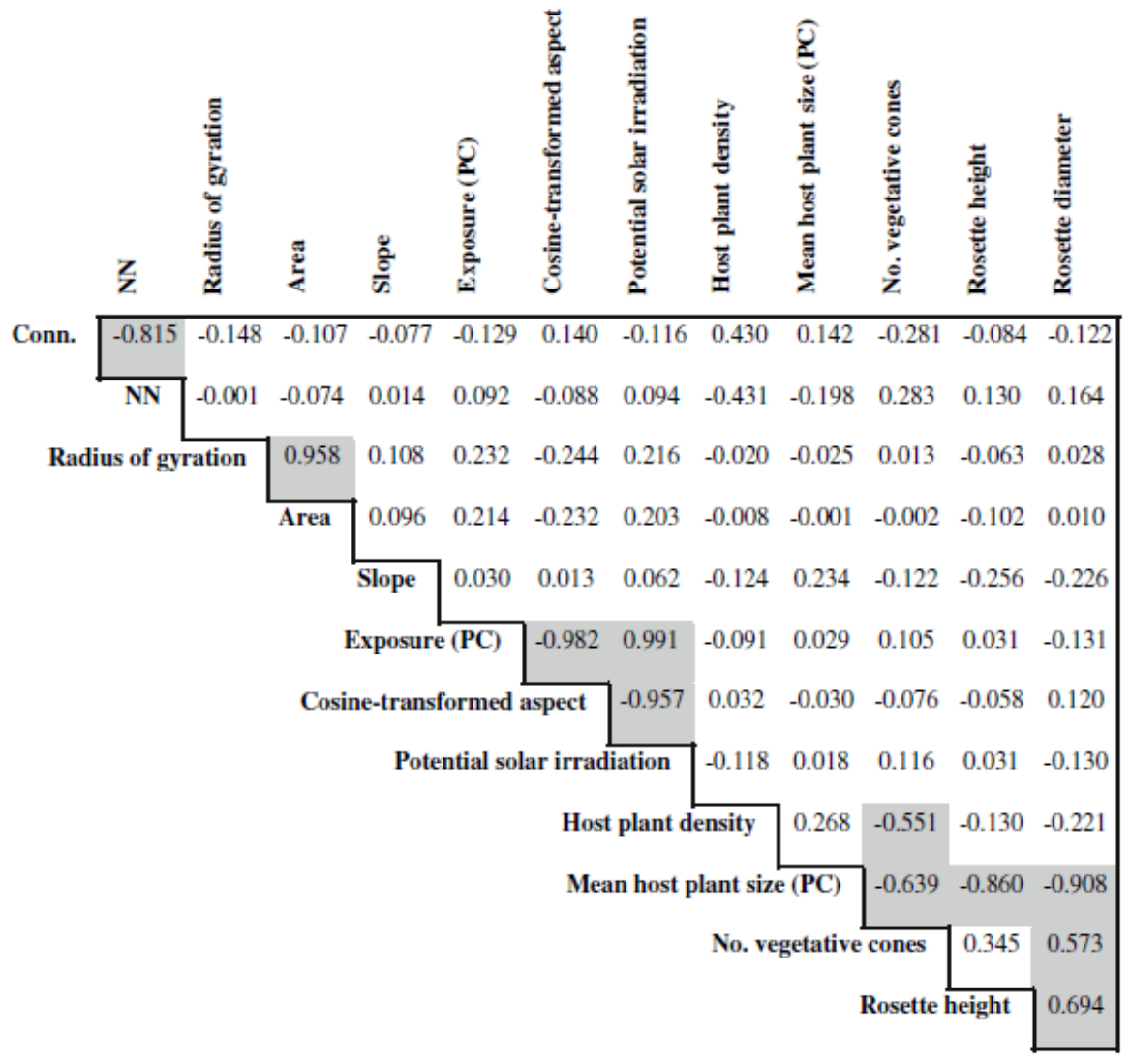




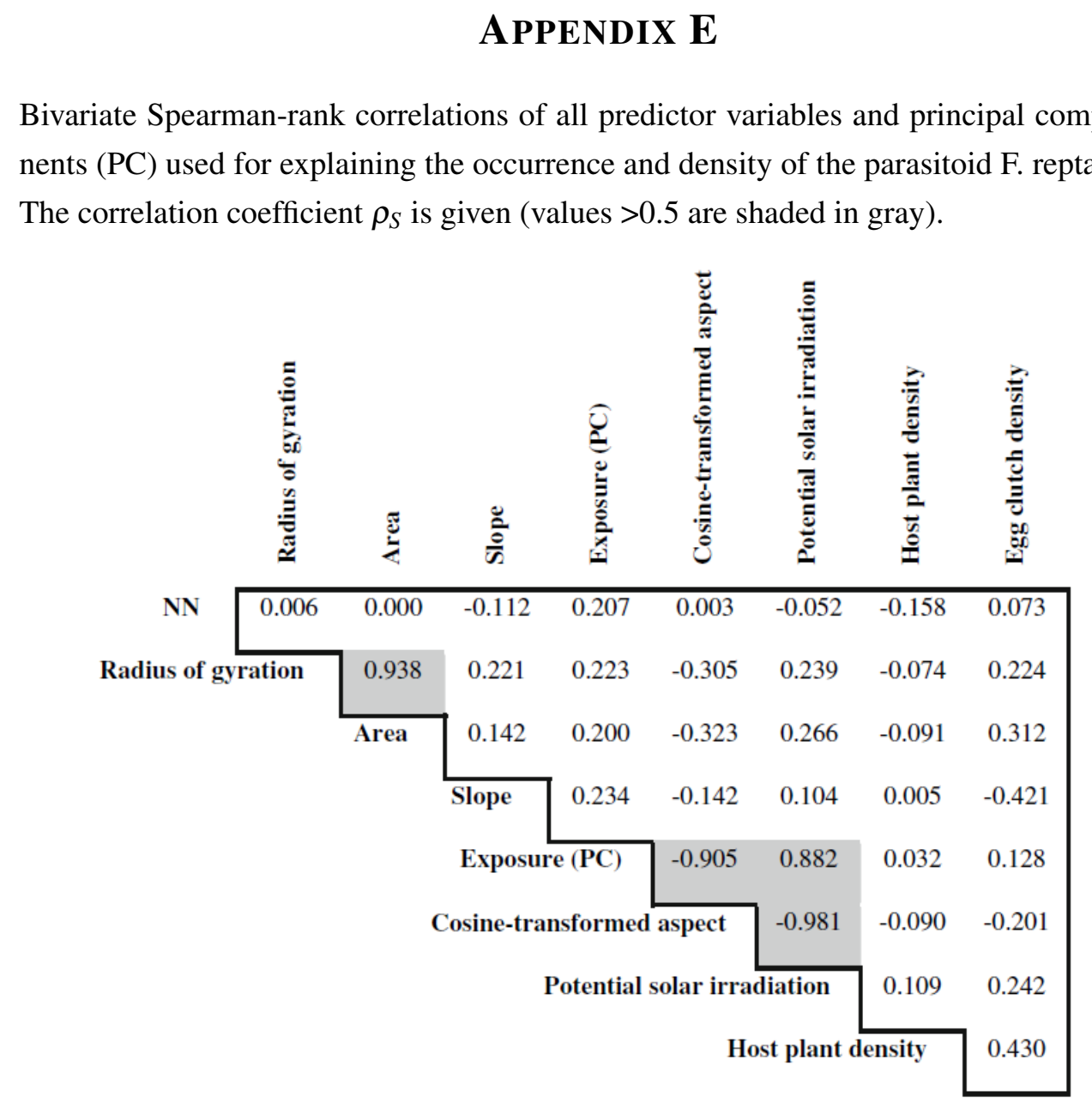




\section{REFERENCES}

Bach, C. E. (1988). Effects of host plant patch size on herbivore density: patterns. Ecology 69: 1090-1102. 12

Bach, M. (1851). Entwickelungs-Geschichte von Cassida austriaca Hbr. Entomologische Zeitung 12: 158-159. 2

Bacher, S. \& Luder, S. (2005). Picky predators and the function of the faecal shield of a cassidine larva. Functional Ecology 19: 263-272. 3, 13

Bayerisches Landesamt für Umweltschutz (2003). Rote Liste gefährdeter Tiere Bayerns. In: Schriftenreihe des Landesamts für Umweltschutz, vol. 166, Bayerisches Landesamt für Umweltschutz, Augsburg, Germany. 2

Berggren, A., Birath, B. \& Kindvall, O. (2002). Effect of corridors and habitat edges on dispersal behavior, movement rates, and movement angles in Roesel's bush-cricket (Metrioptera roeseli). Conservation Biology 16: 1562-1569. 11

Binzenhöfer, B., Schröder, B., Strauss, B., Biedermann, R. \& Settele, J. (2005). Habitat models and habitat connectivity analysis for butterflies and burnet moths - The example of Zygaena carniolica and Coenonympha arcania. Biological Conservation 126: 247-259. 6

Bourgeois, J. \& Scherdlin, P. (1899). Catalogue des Coléoptères des Vosges et des regions limitrophes. Decker, Colmar. 3

Bundesamt für Naturschutz (1998). Rote Liste gefährdeter Tiere Deutschlands. In: Schriftenreihe für Landschaftspflege und Naturschutz, vol. 55, Landwirtschaftsverlag, Münster, Germany. 2

Burnham, K. P. \& Anderson, D. R. (2002). Model selection and multi-model inference: a practical informationtheoretic approach. Springer, New York. 6

Clarke, R. T., Thomas, J. A., Elmes, G. W. \& Hochberg, M. E. (1997). The effects of spatial patterns in habitat quality on community dynamics within a site. Proceedings of the Royal Society B: Biological Sciences 264: 347-354. 2

Connor, E. F., Courtney, A. C. \& Yoder, J. M. (2000). Individuals-area relationships: the relationship between animal population density and area. Ecology 81: 734-748. 12

Cronin, J. T. \& Reeve, J. D. (2005). Host-parasitoid spatial ecology: a plea for a landscape-level synthesis. Proceedings of the Royal Society B: Biological Sciences 272: 2225-2235. 2, 13

Dennis, R. L. H. \& Eales, H. T. (1997). Patch occupancy in Coenonympha tullia (Müller, 1764) (Lepidoptera: Satyrinae): habitat quality matters as much as patch size and isolation. Journal of Insect Conservation 1: 167-176. 2, 13

Dennis, R. L. H., Shreeve, T. G. \& van Dyck, H. (2006). Habitats and resources: the need for a resource-based definition to conserve butterflies. Biodiversity and Conservation 15: 1943-1966. 2

Eber, S. (2001). Multitrophic interactions: The population dynamics of spatially structured plant-herbivore-parasitoid systems. Basic and Applied Ecology 2: 27-33. 2

Elsner, O. (1994). Geplantes Naturschutzgebiet “Südlicher Haßbergetrauf” im Landkreis Haßberge. Gutachten im Auftrag der Regierung von Unterfranken. Institut für Vegetationskunde und Landschaftsökologie, HemhofenZeckern. 3

Ewers, R. M. \& Didham, R. K. (2006). Confounding factors in the detection of species responses to habitat fragmentation. Biological Reviews 81: 117-142. 1, 11, 12

Fahrig, L. (2001). How much habitat is enough? Biological Conservation 100: 65-74. 1

Fahrig, L. (2003). Effects of habitat fragmentation on biodiversity. Annual Review of Ecology, Evolution, and Systematics 34: 487-515. 1 
Fleishman, E., Ray, C., Sjögren-Gulve, P., Boggs, C. L. \& Murphy, D. D. (2002). Assessing the roles of patch quality, area, and isolation in predicting metapopulation dynamics. Conservation Biology 16: 706-716. 2, 3

Goodwin, B. J. \& Fahrig, L. (2002). How does landscape structure influence landscape connectivity? Oikos 99: 552570. 12

Graser, K. (1984). Thüringer Funde von Cassida (U. G. Lordiconia RTTR) canaliculata LAICH. 1781 (Col., Chrysomelidae). Entomologische Nachrichten und Berichte 28: 86-87. 3

Gustafson, E. J. \& Gardner, R. H. (1996). The effect of landscape heterogeneity on the probability of patch colonization. Ecology 77: 94-107. 12

Hanley, J. A. \& McNeil, B. J. (1982). The meaning and use of the area under a receiver operating characteristic (ROC) curve. Radiology 143: 29-36. 6

Hanski, I. (1998). Metapopulation dynamics. Nature 396: 41-49. 2, 5

Hanski, I. \& Gaggiotti, O. E. (eds.) (2004). Ecology, Genetics, and Evolution of Metapopulations. Elsevier Academic Press, Amsterdam. 2, 11

Hanski, I. \& Ovaskainen, O. (2003). Metapopulation theory for fragmented landscapes. Theoretical Population Biology 64: 119-127. 3

Harrell, F. E. J. (2001). Regression modeling strategies: with applications to linear models, logistic regression, and survival analysis. Springer, New York. 6

Harrell, F. E. J. (2005). Design: Design package. R package version 2.0-12, URL http : / / www. r-project. org. 6

Harrell, F. E. J. \& contributions from many other users (2006). Hmisc: Harrell Miscellaneous. R package version 3.1-1, URL http: / / www.r-project.org. 6

Haynes, K. J., Dillemuth, F. P., Anderson, B. J., Hakes, A. S., Jackson, H. B., Jackson, S. E. \& Cronin, J. T. (2007). Landscape context outweighs local habitat quality in its effects on herbivore dispersal and distribution. Oecologia 151: $431-441.2$

Heikkinen, R. K., Luoto, M., Kuussaari, M. \& Pöyry, J. (2005). New insights into butterfly-environment relationships using partitioning methods. Proceedings of the Royal Society B: Biological Sciences 272: 2203-2210. 6

Hein, S., Voss, J., Poethke, H. J. \& Schröder, B. (2007). Habitat suitability models for the conservation of thermophilic grasshoppers and bush crickets - simple or complex? Journal of Insect Conservation 11: 221-240. 3, 15

Heisswolf, A., Obermaier, E. \& Poethke, H. J. (2005). Selection of large host plants for oviposition by a monophagous leaf beetle: nutritional quality or enemy-free space? Ecological Entomology 30: 299-306. 3

Heisswolf, A., Poethke, H. J. \& Obermaier, E. (2006). Multitrophic influences on egg distribution in a specialized leaf beetle at multiple spatial scales. Basic and Applied Ecology 7: 565-576. 3, 13

Hosmer, D. W. \& Lemeshow, S. (2000). Applied Logistic Regression. Wiley, New York. 6

Hunter, M. D. (2002). Landscape structure, habitat fragmentation, and the ecology of insects. Agricultural and Forest Entomology 4: 159-166. 1, 2

Keitt, T. H., Urban, D. L. \& Milne, B. T. (1997). Detecting critical scales in fragmented landscapes. Conservation Ecology [online] 1: 4, URL http: / / www. consecol.org/vol1/iss1/art 4/. 5

Krauss, J., Steffan-Dewenter, I., Müller, C. B. \& Tscharntke, T. (2005). Relative importance of resource quantity, isolation and habitat quality for landscape distribution of a monophagous butterfly. Ecography 28: 465-474. 12 
Krauss, J., Steffan-Dewenter, I. \& Tscharntke, T. (2004). Landscape occupancy and local population size depends on host plant distribution in the butterfly Cupido minimus. Biological Conservation 120: 355-361. 12

Kuhn, W. \& Kleyer, M. (1999/2000). A statistical habitat model for the Blue Winged Grasshopper (Oedipoda caerulescens) considering the habitat connectivity. Zeitschrift für Ökologie und Naturschutz 8: 207-218. 11

Mac Nally, R. (2000). Regression and model-building in conservation biology, biogeography and ecology: The distinction between - and reconciliation of - "predictive" and "explanatory" models. Biodiversity and Conservation 9: $655-671.6$

Mac Nally, R. (2002). Multiple regression and inference in ecology and conservation biology: further comments on identifying important predictor variables. Biodiversity and Conservation 11: 1397-1401. 6

Mardia, K. V., Kent, J. T. \& Bibby, J. M. (1979). Multivariate Analysis. Academic Press, London. 6

McGarigal, K. (2001). Fragstats: Spatial Pattern Analysis Program for Quantifying Landscape Structure. Version 3.3. URL http: //www. umass. edu/landeco/research/fragstats/fragstats.html. 5

Moilanen, A. \& Hanski, I. (1998). Metapopulation dynamics: effects of habitat quality and landscape structure. Ecology 79: 2503-2515. 2

Moilanen, A. \& Nieminen, M. (2002). Simple connectivity measures in spatial ecology. Ecology 83: 1131-1145. 11

Nagelkerke, N. J. D. (1991). A note on the general definition of the coefficient of determination. Biometrika 78: 691-692. 6

R Development Core Team (2005). $R$ : A language and environment for statistical computing. R Foundation for Statistical Computing, Vienna, Austria, URL http: / /www.r-project.org. 6

Reitter, E. (1912). Fauna Germanica, Käfer. Lutz, Stuttgart. 3

Ricketts, T. H. (2001). The matrix matters: effective isolation in fragmented landscapes. American Naturalist 158: 87-99. 12

Rosenberg, D. K., Noon, B. R. \& Meslow, E. C. (1997). Biological corridors: form, function, and efficacy. BioScience 47: 677-687. 11

Rudner, M., Biedermann, R., Schröder, B. \& Kleyer, M. (2007). Integrated Grid Based Ecological and Economic (INGRID) landscape model - A tool to support landscape management decisions. Environmental Modelling \& Software 22: 177-187. 3, 4

Schröder, B. (2006). ROC \& AUC-Calculation-evaluating the predictive performance of habitat models. URL htt $\mathrm{p}$ : //brandenburg.geoecology.uni-potsdam.de/users/schroeder/download.html. 6

Steinhausen, W. (1949). Morphologie, Biologie und Ökologie der Entwicklungsstadien der in Niedersachsen heimischen Schildkäfer (Cassidinae Chrysomelidae Coleoptera) und deren Bedeutung für die Landwirtschaft. Ph.D. thesis, Technische Hochschule Braunschweig. 2

Swets, J. A. (1988). Measuring the accuracy of diagnostic systems. Science 240: 1285-1293. 6

Thomas, J. A., Bourn, N. A. D., Clarke, R. T., Stewart, K. E., Simcox, D. J., Pearman, G. S., Curtis, R. \& Goodger, B. (2001). The quality and isolation of habitat patches both determine where butterflies persist in fragmented landscapes. Proceedings of the Royal Society B: Biological Sciences 268: 1791-1796. 2, 3, 12, 13

Thomas, J. A., Clarke, R. T., Elmes, G. W. \& Hochberg, M. E. (1998). Population dynamics in the genus Maculinea. In: Dempster, J. P. \& McLean, I. F. G. (eds.) Insect Population Dynamics: In Theory and Practice, Chapman \& Hall, London, pp. 261-290. 2

Trautner, J., Geigenmüller, K. \& Bense, U. (1989). Käfer beobachten, bestimmen. Neumann-Neudamm, Melsungen. 3 
Tscharntke, T. \& Brandl, R. (2004). Plant-insect interactions in fragmented landscapes. Annual Review of Entomology 49: 405-430. 13

Tscharntke, T., Steffan-Dewenter, I., Kruess, A. \& Thies, C. (2002). Characteristics of insect populations on habitat fragments: a mini review. Ecological Research 17: 229-239. 2, 11

van Nouhuys, S. \& Hanski, I. (2002). Multitrophic interactions in space: metacommunity dynamics in fragmented landscapes. In: Tscharntke, T. \& Hawkins, B. A. (eds.) Multitrophic Level Interactions, Cambridge University Press, Cambridge, pp. 124-147. 2

Venables, W. N. \& Ripley, B. D. (2002). Modern Applied Statistics with S. Springer, New York. 6

Walsh, C. \& Mac Nally, R. (2007). hier.part: hierarchical partitioning. R package version 1.0-2. URL http: / / www . r-project.org. 6

Wencker, J. \& Silbermann, G. (1866). Catalogue des Coléoptères de l'Alsace et des Vosgues. Silbermann, Strasbourg. 3

Wiegand, T., Moloney, K. A., Naves, J. \& Knauer, F. (1999). Finding the missing link between landscape structure and population dynamics: a spatially explicit perspective. American Naturalist 154: 605-627. 2 